\title{
FOREIGN DEMAND FOR DOMESTIC CURRENCY AND THE OPTIMAL RATE OF INFLATION
}

\author{
Stephanie Schmitt-Grohé \\ Martín Uribe
}

Working Paper 15494

http://www.nber.org/papers/w15494

\author{
NATIONAL BUREAU OF ECONOMIC RESEARCH \\ 1050 Massachusetts Avenue \\ Cambridge, MA 02138 \\ November 2009
}

The views expressed herein are those of the author(s) and do not necessarily reflect the views of the National Bureau of Economic Research.

NBER working papers are circulated for discussion and comment purposes. They have not been peerreviewed or been subject to the review by the NBER Board of Directors that accompanies official NBER publications.

(C) 2009 by Stephanie Schmitt-Grohé and Martín Uribe. All rights reserved. Short sections of text, not to exceed two paragraphs, may be quoted without explicit permission provided that full credit, including (๑) notice, is given to the source. 
Foreign Demand for Domestic Currency and the Optimal Rate of Inflation

Stephanie Schmitt-Grohé and Martín Uribe

NBER Working Paper No. 15494

November 2009

JEL No. E41,E5

\begin{abstract}
$\underline{\text { ABSTRACT }}$
More than half of U.S. currency circulates abroad. As a result, much of the seignorage income of the United States is generated outside of its borders. In this paper we characterize the Ramsey-optimal rate of inflation in an economy with a foreign demand for its currency. In the absence of such demand, the model implies that the Friedman rule-deflation at the real rate of interest-maximizes the utility of the representative domestic consumer. We show analytically that once a foreign demand for domestic currency is taken into account, the Friedman rule ceases to be Ramsey optimal. Calibrated versions of the model that match the range of empirical estimates of the size of foreign demand for U.S. currency deliver Ramsey optimal rates of inflation between 2 and 10 percent per annum. The domestically benevolent government finds it optimal to impose an inflation tax as a way to extract resources from the rest of the world in the form of seignorage revenue.
\end{abstract}

Stephanie Schmitt-Grohé

Department of Economics

Columbia University

New York, NY 10027

and NBER

stephanie.schmittgrohe@columbia.edu

Martín Uribe

Department of Economics

Columbia University

International Affairs Building

New York, NY 10027

and NBER

martin.uribe@columbia.edu 


\section{Introduction}

More than half of U.S. currency circulates abroad. Porter and Judson (1996), for instance, estimate that at the end of $1995 \$ 200$ to $\$ 250$ billion of the $\$ 375$ billion of U.S. currency in circulation outside of banks was held abroad. The foreign demand for U.S. currency has remained strong across time. The 2006 Treasury, Federal Reserve, and Secret Service report on the use of U.S. currency abroad, issued a decade after the publication of Porter and Judson, estimates that as of December 2005 about $\$ 450$ billion of the $\$ 760$ billion of circulated U.S. banknotes are held in other countries.

The estimated size of the foreign demand for U.S. currency suggests that much of the seignorage income of the United States is generated outside of its borders. A natural question is therefore whether the inflation rate that maximizes the utility of the representative domestic consumer is influenced by the presence of a foreign demand for its country's currency. In this paper we address this issue within the context of a dynamic Ramsey problem. We show that the mere existence of a foreign demand for domestic money can, under plausible parameterizations, justify sizable deviations from the rate of inflation associated with the Friedman rule. The basic intuition behind this finding is that adherence to the negative rate of inflation associated with the Friedman rule would represent a welfare-decreasing transfer of real resources by the domestic economy to the rest of the world, as nominal money balances held abroad increase in real terms at the rate of deflation. A benevolent government weighs this cost against the benefit of keeping the opportunity cost of holding money low to reduce transactions costs for domestic agents. Our analytical results show that this tradeoff is resolved in favor of deviating from the Friedman rule. Indeed, our quantitative analysis suggests that for plausible calibrations that capture the range of estimates of the size of the foreign demand for U.S. currency the Ramsey-optimal rate of inflation lies between 2 and 10 percent per annum.

The reason why the Ramsey government finds it optimal to collect seignorage revenues from the rest of the world is not the fact that such revenues allow the fiscal authority to lower distortionary taxes. Rather, it is the fact that the imposition of an inflation tax allows the domestic government to engineer an indirect transfer of real resources from foreign consumers to domestic consumers. We highlight this incentive by establishing that in the presence of a foreign demand for domestic currency the Friedman rule is suboptimal even when the domestic government has access to lump-sum taxation.

The rest of the paper is organized as follows: Section 2 presents a dynamic monetary model with a foreign demand for domestic currency. Section 3 establishes that the Friedman rule is optimal in the absence of a foreign demand for domestic currency and that it fails to 
be optimal in the presence of such demand. Section 4 provides estimates of the optimal rate of inflation in the context of a calibrated version of the model. Section 5 demonstrates that the optimality of inflation when the domestic currency is held abroad obtains even when the domestic government has access to lump-sum taxation. Section 6 concludes.

\section{The Model}

Consider an economy populated by a large number of identical households. Each household has preferences defined over sequences of consumption and leisure and described by the utility function

$$
\sum_{t=0}^{\infty} \beta^{t} U\left(c_{t}, h_{t}\right),
$$

where $c_{t}$ denotes consumption, $h_{t}$ denotes labor effort, and $\beta \in(0,1)$ denotes the subjective discount factor. The single period utility function $U$ is assumed to be increasing in consumption, decreasing in effort, and strictly concave.

A domestic demand for real balances is introduced into the model by assuming that nominal money holdings, denoted $M_{t}^{d}$, facilitate consumption purchases. Specifically, consumption purchases are subject to a proportional transaction cost $s\left(v_{t}\right)$ that is decreasing in the household's money-to-consumption ratio, or consumption-based money velocity,

$$
v_{t}=\frac{P_{t} c_{t}}{M_{t}^{d}},
$$

where $P_{t}$ denotes the nominal price of the consumption good in period $t$. The transaction cost function, $s(v)$, satisfies the following assumptions: (a) $s(v)$ is nonnegative and twice continuously differentiable; (b) There exists a level of velocity $\underline{v}>0$, to which we refer as the satiation level of money, such that $s(\underline{v})=s^{\prime}(\underline{v})=0 ;(\mathrm{c})(v-\underline{v}) s^{\prime}(v)>0$ for $v \neq \underline{v}$; and (d) $2 s^{\prime}(v)+v s^{\prime \prime}(v)>0$ for all $v \geq \underline{v}$. Assumption (b) ensures that the Friedman rule, i.e., a zero nominal interest rate, need not be associated with an infinite demand for money. It also implies that both the transaction cost and the distortion it introduces vanish when the nominal interest rate is zero. Assumption (c) guarantees that in equilibrium money velocity is always greater than or equal to the satiation level. Assumption (d) ensures that the demand for money is a decreasing function of the nominal interest rate.

Households are assumed have access to one-period nominal bonds, denoted $B_{t}$, which carry a gross nominal interest rate of $R_{t}$ when held from period $t$ to period $t+1$. Households supply labor services to competitive labor markets at the real wage rate $w_{t}$. In addition, households receive profit income in the amount $\Pi_{t}$ from the ownership of firms, and pay 
income taxes at the flat rate $\tau_{t}$. The flow budget constraint of the household in period $t$ is then given by:

$$
P_{t} c_{t}\left[1+s\left(v_{t}\right)\right]+M_{t}^{d}+B_{t}=M_{t-1}^{d}+R_{t-1} B_{t-1}+P_{t}\left(1-\tau_{t}\right)\left(w_{t} h_{t}+\Pi_{t}\right)
$$

In addition, it is assumed that the household is subject to the following borrowing limit that prevents it from engaging in Ponzi-type schemes:

$$
\lim _{j \rightarrow \infty} \frac{M_{t+j}^{d}+R_{t+j} B_{t+j}}{\prod_{s=0}^{j} R_{t+s}} \geq 0 .
$$

This restriction states that in the long run household's net nominal liabilities must grow at a rate smaller than the nominal interest rate. It rules out, for example, schemes in which households roll over their net debts forever.

The household chooses sequences $\left\{c_{t}, h_{t}, v_{t}, M_{t}^{d}, B_{t}\right\}_{t=0}^{\infty}$ to maximize (1) subject to (2)-(4), taking as given the sequences $\left\{P_{t}, \tau_{t}, R_{t}, w_{t}, \Pi_{t}\right\}_{t=0}^{\infty}$ and the initial condition $M_{-1}^{d}+R_{-1} B_{-1}$. The first-order conditions associated with the household's maximization problem are (2), (3), (4) holding with equality, and

$$
\begin{gathered}
v_{t}^{2} s^{\prime}\left(v_{t}\right)=\frac{R_{t}-1}{R_{t}} \\
-\frac{U_{h}\left(c_{t}, h_{t}\right)}{U_{c}\left(c_{t}, h_{t}\right)}=\frac{\left(1-\tau_{t}\right) w_{t}}{1+s\left(v_{t}\right)+v_{t} s^{\prime}\left(v_{t}\right)} \\
\frac{U_{c}\left(c_{t}, h_{t}\right)}{1+s\left(v_{t}\right)+v_{t} s^{\prime}\left(v_{t}\right)}=\beta \frac{R_{t} P_{t}}{P_{t+1}} \frac{U_{c}\left(c_{t+1}, h_{t+1}\right)}{\left[1+s\left(v_{t+1}\right)+v_{t+1} s^{\prime}\left(v_{t+1}\right)\right]} .
\end{gathered}
$$

Optimality condition (5) can be interpreted as a domestic demand for money or a domestic liquidity preference function. Given our maintained assumptions about the transactions technology $s\left(v_{t}\right)$, the implied domestic money demand function is decreasing in the gross nominal interest rate $R_{t}$. Further, our assumptions imply that as the interest rate vanishes, or $R_{t}$ approaches unity, the domestic demand for money reaches a finite maximum level given by $c_{t} / \underline{v}$. At this level of money demand, households are able to perform transactions costlessly, as the transactions cost, $s\left(v_{t}\right)$, becomes nil. Optimality condition (6) shows that a level of money velocity above the satiation level $\underline{v}$, or, equivalently, an interest rate greater than zero, introduces a wedge, given by $1+s\left(v_{t}\right)+v_{t} s^{\prime}\left(v_{t}\right)$, between the marginal rate of substitution of consumption for leisure and the real wage rate. In addition, the labor supply distortion has a tax component given by $1-\tau_{t}$, making the total wedge between the marginal rate of substitution of leisure for consumption ad the real wage rate equal 
to $\left(1-\tau_{t}\right) /\left[1+s\left(v_{t}\right)+v_{t} s^{\prime}\left(v_{t}\right)\right]$. This wedge induces households to move to an inefficient allocation featuring too much leisure and too little consumption. The wedge is increasing in the nominal interest rate and in the income tax rate, implying that the larger is the nominal interest rate or the income tax rate, the more distorted is the consumption-leisure choice. Optimality condition (7) is a Fisher equation stating that the nominal interest rate must be equal to the sum of the expected rate of inflation and the real rate of interest. It is clear from the Fisher equation that intertemporal movements in the nominal interest rate create a distortion in the real interest rate perceived by households.

Final goods are produced by competitive firms using the technology $F\left(h_{t}\right)$ that takes labor as the only factor input. The production function $F$ is assumed to be increasing and concave. Firms choose labor input to maximize profits, which are given by

$$
\Pi_{t}=F\left(h_{t}\right)-w_{t} h_{t}
$$

The first-order condition associated with the firm's profit maximization problem gives rise to the following demand for labor

$$
F^{\prime}\left(h_{t}\right)=w_{t}
$$

The rest of the world demands domestic nominal money balances in the amount $M_{t}^{f}$. We assume that the demand by foreigners for real domestic currency is a function of the level of foreign aggregate activity, denoted $y_{t}^{f}$, and the domestic nominal interest rate:

$$
\left(v_{t}^{f}\right)^{2} \tilde{s}^{\prime}\left(v_{t}^{f}\right)=\frac{R_{t}-1}{R_{t}}
$$

where $v_{t}^{f}$ is defined as

$$
v_{t}^{f}=\frac{P_{t} y_{t}^{f}}{M_{t}^{f}} .
$$

The transactions cost technology $\tilde{s}$ satisfies the same properties as the domestic transactions cost function $s$.

The government prints money, issues nominal, one-period bonds, and levies taxes to finance an exogenous stream of public consumption, denoted $g_{t}$ and interest obligations on the outstanding public debt. Accordingly, the government's sequential budget constraint is given by

$$
M_{t}^{d}+M_{t}^{f}+B_{t}=M_{t-1}^{d}+M_{t-1}^{f}+R_{t-1} B_{t-1}+P_{t} g_{t}-P_{t} \tau_{t} F\left(h_{t}\right)
$$

Implicit in the sequential budget constraint of the government is the assumption that the government's consumption transactions are not subject to a monetary friction like the one 
imposed on private purchases of goods.

Combining the household's and the government's sequential budget constraints yields the following aggregate resource constraint

$$
\left[1+s\left(v_{t}\right)\right] c_{t}+g_{t}=F\left(h_{t}\right)+\frac{M_{t}^{f}-M_{t-1}^{f}}{P_{t}} .
$$

It is clear from this resource constraint that the domestic economy collects seignorage revenue from foreigners whenever nominal money balances held by foreigners increase.

A competitive equilibrium is a set of sequences $\left\{v_{t}, w_{t}, v_{t}^{f}, c_{t}, h_{t}, M_{t}^{d}, M_{t}^{f}, B_{t}, P_{t}\right\}_{t=0}^{\infty}$ satisfying (2), (4) holding with equality, (5)-(12), and

$$
R_{t} \geq 1
$$

given policies $\left\{R_{t}, \tau_{t}\right\}_{t=0}^{\infty}$, the exogenous sequences $\left\{g_{t}, y_{t}^{f}\right\}_{t=0}^{\infty}$, and the initial conditions $M_{-1}^{d}+R_{-1} B_{-1}>0$ and $M_{-1}^{f}$. Equilibrium condition (13) imposes a zero lower bound on the nominal interest rate. Such a bound is required to prevent the possibility of unbounded arbitrage profits created by taking short positions in nominal bonds and long positions in nominal fiat money, which would result in ill-defined demands for consumption goods by households.

Our primary goal is to characterize the Ramsey optimal rate of inflation. To this end, we begin by deriving the primal form of the competitive equilibrium. Then we state the Ramsey problem. And finally we characterize optimal fiscal and monetary policy.

\subsection{The Primal Form of the Competitive Equilibrium}

Following a long-standing tradition in Public Finance, we study optimal policy using the primal-form representation of the competitive equilibrium. Finding the primal form involves the elimination of all prices and tax rates from the equilibrium conditions, so that the resulting reduced form involves only real variables. In our economy, the real variables that appear in the primal form are consumption, hours, and domestic and foreign money velocity. The primal form of the equilibrium conditions consists of two equations. One equation is a feasibility constraint, given by the resource constraint (12), which must hold at every date. The other equation is a single, present-value constraint known as the implementability constraint. The implementability constraint guarantees that at the prices and quantities associated with every possible competitive equilibrium, the present discounted value of consolidated government surpluses equals the government's total initial liabilities.

Formally, given the initial conditions $\left(R_{-1} B_{-1}+M_{-1}^{d}\right)$ and $M_{-1}^{f}$ and the initial price level 
$P_{0}$, sequences $\left\{c_{t}, h_{t}, v_{t}\right\}_{t=0}^{\infty}$ satisfy the feasibility condition

$$
\left[1+s\left(v_{0}\right)\right] c_{0}+g_{0}=F\left(h_{0}\right)+\frac{y_{0}^{f}}{\chi\left(v_{0}\right)}-\frac{M_{-1}^{f}}{P_{0}}
$$

in period 0 and

$$
\left[1+s\left(v_{t}\right)\right] c_{t}+g_{t}=F\left(h_{t}\right)+\frac{y_{t}^{f}}{\chi\left(v_{t}\right)}-\frac{y_{t-1}^{f}}{\chi\left(v_{t-1}\right)}\left(1-v_{t-1}^{2} s^{\prime}\left(v_{t-1}\right)\right) \frac{U_{c}\left(c_{t-1}, h_{t-1}\right)}{\gamma\left(v_{t-1}\right)} \frac{\gamma\left(v_{t}\right)}{\beta U_{c}\left(c_{t}, h_{t}\right)},
$$

for all $t>0$, the implementability constraint

$$
\sum_{t=0}^{\infty} \beta^{t}\left\{U_{c}\left(c_{t}, h_{t}\right) c_{t}+U_{h}\left(c_{t}, h_{t}\right) h_{t}\right\}=\frac{U_{c}\left(c_{0}, h_{0}\right)}{1+s\left(v_{0}\right)+v_{0} s^{\prime}\left(v_{0}\right)} \frac{R_{-1} B_{-1}+M_{-1}^{d}}{P_{0}}
$$

and

$$
v_{t} \geq \underline{v} \quad \text { and } \quad v_{t}^{2} s^{\prime}\left(v_{t}\right)<1,
$$

if and only if they also satisfy the set of equilibrium conditions (2), (4) holding with equality, and (5)-(13). The function

$$
v_{t}^{f}=\chi\left(v_{t}\right)
$$

is defined as the solution for $v^{f}$ of the implicit function $v^{2} s^{\prime}(v)-\left(v^{f}\right)^{2} \tilde{s}^{\prime}\left(v^{f}\right)=0$. Appendix 7.1 presents the proof of this statement.

\section{The Ramsey Equilibrium}

The government is assumed to be benevolent towards domestic residents. This means that the welfare function of the government coincides with the lifetime utility of the domestic representative agent, and that it is independent of the level of utility of foreign residents. The Ramsey problem consists in choosing a set of strictly positive sequences $\left\{c_{t}, h_{t}, v_{t}\right\}_{t=0}^{\infty}$ to maximize the utility function (1) subject to (14), (15), (16), $v_{t} \geq \underline{v}$, and $v_{t}^{2} s^{\prime}\left(v_{t}\right)<1$, given $R_{-1} B_{-1}+M_{-1}, M_{-1}^{f}$, and $P_{0}$. We fix the initial price level arbitrarily to keep the Ramsey planner from engineering a large unexpected initial inflation aimed at reducing the real value of predetermined nominal government liabilities. This assumption is regularly maintained in the literature on optimal monetary and fiscal policy.

Write the feasibility constraint (15) as $H\left(c_{t}, c_{t-1}, h_{t}, h_{t-1}, v_{t}, v_{t-1}\right)=0$ and the implementability constraint (16) as $\sum_{t=0}^{\infty} \beta^{t} K\left(c_{t}, h_{t}\right)=A\left(c_{0}, h_{0}, v_{0}\right)$. Let the Lagrange multiplier on the feasibility constraint (15) be denoted by $\psi_{t}$, the Lagrange multiplier on the imple- 
mentability constraint (16) be denoted by $\lambda$, and the Lagrange multiplier on the constraint $v_{t} \geq \underline{v}$ be denoted by $\mu_{t}$. Then, for any $t>0$, the first-order conditions of the Ramsey problem are

$$
\begin{gathered}
U_{c}\left(c_{t}, h_{t}\right)+\lambda K_{c}\left(c_{t}, h_{t}\right)+\psi_{t} H_{1}\left(c_{t}, c_{t-1}, h_{t}, h_{t-1}, v_{t}, v_{t-1}\right)+\beta \psi_{t+1} H_{2}\left(c_{t+1}, c_{t}, h_{t+1}, h_{t}, v_{t+1}, v_{t}\right)=0 \\
U_{h}\left(c_{t}, h_{t}\right)+\lambda K_{h}\left(c_{t}, h_{t}\right)+\psi_{t} H_{3}\left(c_{t}, c_{t-1}, h_{t}, h_{t-1}, v_{t}, v_{t-1}\right)+\beta \psi_{t+1} H_{4}\left(c_{t+1}, c_{t}, h_{t+1}, h_{t}, v_{t+1}, v_{t}\right)=0 \\
\psi_{t} H_{5}\left(c_{t}, c_{t-1}, h_{t}, h_{t-1}, v_{t}, v_{t-1}\right)+\beta \psi_{t+1} H_{6}\left(c_{t+1}, c_{t}, h_{t+1}, h_{t}, v_{t+1}, v_{t}\right)+\mu_{t}=0 \\
\left(v_{t}-\underline{v}\right) \mu_{t}=0 ; \quad \mu_{t} \geq 0 ; \quad v_{t} \geq \underline{v} .
\end{gathered}
$$

We do not include the constraint $v_{t}^{2} s^{\prime}\left(v_{t}\right)<1$ in the Lagrangian. Therefore, we must check that the solution to the above system satisfies this constraint.

When the foreign demand for domestic currency is nil, $M_{t}^{f}=0$, any policy other than the Friedman rule fails to be Ramsey optimal. To see this, note that when $M_{t}^{f}=0$ (or, equivalently, when $y^{f} / \chi\left(v_{t}\right)=0$ ), the first-order condition of the Ramsey problem with respect to $v_{t}$, equation $(20)$, becomes

$$
-\psi_{t} s^{\prime}\left(v_{t}\right) c_{t}+\mu_{t}=0
$$

Consider any level of velocity $v_{t}$ greater than $\underline{v}$, the level called for by the Friedman rule. Our assumptions regarding the transactions cost technology imply that $s^{\prime}(v)>0$ for any $v_{t}>\underline{v}$. Also, the fact that the period utility function $U$ is strictly increasing implies that $\psi_{t}>0$. It then follows from the above expression that $\mu_{t}$ is strictly positive when $v_{t}>\underline{v}$. This result and the fact that, by assumption $v_{t}>\underline{v}$ imply that optimality condition (21) is violated. We conclude that in the case of no foreign demand for domestic currency, if a Ramsey equilibrium exists, then it must be characterized by a zero nominal interest rate for all $t>0$. This is a standard result in the theory of optimal monetary and fiscal policy.

\subsection{Failure of the Friedman Rule}

We now present the main result of this paper, namely, that the Friedman rule ceases to be Ramsey optimal in the presence of a foreign demand for domestic currency. To facilitate the exposition, we restrict attention to the steady state of the Ramsey equilibrium. That is, we restrict attention to solutions to (15) and (18)-(21) in which the endogenous variables $c_{t}, h_{t}$, $v_{t}, \psi_{t}$ and $\mu_{t}$ are constant given constant levels for the exogenous variables $g_{t}$ and $y_{t}^{f}$. To establish the failure of the Friedman rule when $M^{f}>0$, we show that a Ramsey equilibrium 
in which $v_{t}$ equals $\underline{v}$ is impossible. In the steady state, the optimality condition (20) when evaluated at $v_{t}=\underline{v}$ becomes:

$$
\frac{y^{f}}{\chi(\underline{v})} s^{\prime \prime}(\underline{v}) \underline{v}\left(1-\frac{1}{\beta}+\underline{v}\right)+\mu=0 .
$$

Under our maintained assumptions regarding the transactions cost technology, $s^{\prime \prime}(\underline{v})$ is positive. Also, under reasonable calibrations, the constant $1 / \beta-1$, which equals the steady-state real interest rate, is smaller than the velocity level $\underline{v}$. Then, the first term in the above expression is positive. This implies that the multiplier $\mu$ must be negative, which violates optimality condition $(21)^{1}$

We conclude that in the presence of a foreign demand for domestic currency, if a Ramsey equilibrium exists, it involves a deviation from the Friedman rule. The intuition behind this result is that the presence of a foreign demand for domestic currency introduces an incentive for the fiscal authority to inflate in order to extract resources, in the form of seignorage, from the rest of the world (whose welfare does not enter the domestic planner's objective function). Indeed, at any negative inflation rate (and, most so at the level of inflation consistent with the Friedman rule), the domestic country actually has derives negative seignorage income from the rest of the world, because foreign money holdings increase in real value as the price level falls. On the other hand, levying an inflation tax on foreign money holdings comes at the cost of taxing domestic money holdings as well. In turn, the domestic inflation tax entails a welfare loss, because domestic households must pay elevated transaction costs as they are forced to economize on real balances. Thus, the Ramsey planner faces a tradeoff between taxing foreign money holdings and distorting the domestic real allocation. We have demonstrated analytically that the resolution of this tradeoff leads to an inflation rate above the one called for by Friedman's rule. We now turn to the question of how large the optimal deviation from the Friedman rule is under a plausible calibration of our model.

\section{Quantifying Deviations from the Friedman Rule}

To gauge the quantitative implications of a foreign demand for money for the Ramsey-optimal rate of inflation, we parameterize the model and solve numerically for the steady state of the

\footnotetext{
${ }^{1}$ One may argue that the assumption $2 s^{\prime}(v)+v s^{\prime \prime}(v)>0$ for all $v \geq \underline{v}$, which implies that the nominal interest rate is a strictly increasing function of $v$ for all $v \geq \underline{v}$ and, in particular, that the elasticity of the liquidity preference function at a zero nominal interest rate is finite, is too restrictive. Suppose instead that the assumption in question is relaxed by assuming that it must hold only for $v>\underline{v}$ but not at $v=\underline{v}$. In this case, a potential solution to the first-order condition of the Ramsey problem with respect to $v_{t}$ is $v=\underline{v}$ provided $s^{\prime \prime}(\underline{v})=0$.
} 
Ramsey equilibrium. We adopt the following functional forms for the period utility function, the transactions cost technology, and the foreign demand for domestic money:

$$
\begin{gathered}
U(c, h)=\ln (c)+\theta \ln (1-h) ; \quad \theta>0, \\
s(v)=A v+B / v-2 \sqrt{A B},
\end{gathered}
$$

and

$$
\chi(v)=v .
$$

The assumed transactions cost function implies that the satiation level of velocity is $\underline{v}=$ $\sqrt{B / A}$ and a demand for money of the form

$$
\frac{M_{t}^{d}}{P_{t}}=\frac{c_{t}}{\sqrt{\frac{B}{A}+\frac{1}{A} \frac{R_{t}-1}{R_{t}}}}
$$

The assumed form for the function $\chi$ implies identical relationships between the nominal interest rate and domestic-money velocity in the domestic and the foreign economies.

We follow Schmitt-Grohé and Uribe (2004) and set $\beta=1 / 1.04, \theta=2.90, B=0.07524$, and $g_{t}=0.04$ for all $t$, which implies a share of government spending of about 20 percent. We set $y^{f}=0.06$ and $A=0.0056$ to match the empirical regularities that about 50 percent of U.S. currency (or about 26 percent of M1) is held outside of the United States and that the M1-to-consumption ratio is about 29 percent. $^{2}$ Finally, we set the level of debt in the Ramsey steady state to 20 percent of GDP. ${ }^{3}$

We develop a numerical algorithm that delivers the exact solution to the steady state of the Ramsey equilibrium. The mechanics of the algorithm are as follows: (1) Pick a positive value of $\lambda$. (2) Given this value of $\lambda$ solve the nonlinear system (15) and (18)-(21) for $c, h$, $v, \psi$, and $\mu$. (3) Calculate $w$ from (8), $\tau$ from (6), $R$ from (5), $\pi$ from (7), $v^{f}$ from (17), $M_{t}^{d} / P_{t}$ from (2), and $M_{t}^{f} / P_{t}$ from (10). (4) Calculate the steady-state debt-to-output ratio, which we denote by $s_{d} \equiv B_{t} /\left(P_{t} y_{t}\right)$, from (11), taking into account that $y=h$. (5) If $s_{d}$ is larger than the calibrated value of 0.2 , lower $\lambda$. If, instead, $s_{d}$ is smaller than the calibrated

\footnotetext{
${ }^{2}$ For an estimate of the amount of U.S. currency circulating abroad, see the joint press release of the Board of Governors of the Federal Reserve System and the Department of the Treasury of October 25, 2006, available online at www.federalreserve.gov.

${ }^{3}$ This debt level implies that the pre-Ramsey reform debt-to-output ratio in the economy without a foreign demand for domestic currency and with a pre-reform inflation rate of 4.2 percent is about 44 percent. The reason why the Ramsey steady-state level of debt is much lower than the pre-Ramsey-reform level is that the reform induces a drop in expected inflation of about 8 percent, which causes a large asset substitution away from government bonds and toward real money balances. The overall level of government liabilities (money plus bonds) is relatively unaffected by the Ramsey reform.
} 
Table 1: Ramsey Policy with Foreign Demand for Domestic Currency

\begin{tabular}{lccccc}
\hline \hline & $\frac{M^{f}}{M^{f}+M^{d}}$ & $\frac{M^{f}+M^{d}}{P c}$ & $\pi$ & $R$ & $\tau$ \\
\hline No Foreign Demand: $y^{f}=0$ & 0.00 & 0.27 & -3.85 & 0.00 & 17.56 \\
Baseline Calibration: $y^{f}=0.06$ & 0.22 & 0.26 & 2.10 & 6.18 & 16.15 \\
Higher Foreign Demand: $y^{f}=0.1$ & 0.32 & 0.24 & 10.52 & 14.94 & 14.64 \\
Low Domestic Demand: $A=0.0014$ & 0.22 & 0.13 & 2.11 & 6.19 & 16.33 \\
High Interest Elasticity: $B=0.0376$ & 0.22 & 0.37 & -0.96 & 3.00 & 16.95 \\
High Debt-to-Output Ratio: $\frac{B}{P y}=0.50$ & 0.22 & 0.26 & 2.21 & 6.30 & 17.50 \\
Lump-Sum Taxes & 0.20 & 0.27 & 0.85 & 4.88 & 0.00 \\
Lump-Sum Taxes and $g_{t}=0$ & 0.19 & 0.27 & 0.59 & 4.62 & - \\
\hline \hline
\end{tabular}

Note: The baseline calibration is: $\mathrm{A}=0.0056, \mathrm{~B}=0.07524, \frac{B}{P y}=0.2, y^{f}=0.06$. The interest rate, $R$, and the inflation rate, $\pi$, are expressed in percent per annum, and the income tax rate, $\tau$, is expressed in percent.

value of 0.2 , then increase the value of $\lambda$. (6) Repeat steps (1)-(5) until $s_{d}$ has converged to its calibrated value.

Table 1 presents our numerical results. The first line of the table shows that when foreign demand for domestic currency is nil, which we capture by setting $y^{f}=0$, then as we have shown analytically above the Friedman rule is Ramsey optimal, that is, the nominal interest rate is zero in the steady state of the Ramsey equilibrium. The inflation rate is -3.85 percent and the income tax rate is about 18 percent. In this case, because the foreign demand for domestic currency is nil, the domestic government has no incentives to levy an inflation tax, as it would generate no revenues from the rest of the world. The second row of the table considers the case that the foreign demand for domestic currency is positive. In particular, we set $y^{f}=0.06$ and obtain that in the Ramsey steady state the ratio of foreign currency to total money is 22 percent and that total money holdings are 26 percent of consumption. Both figures are broadly in line with observation in the U.S. economy. The table shows, again in line with the analytical results obtained above, that the Ramsey optimal rate of interest is positive, that is, the Friedman rule is no longer optimal. Of greater interest however is the size of the deviation from the Friedman rule. The table shows that the Ramsey optimal inflation rate is 2.10 percent per year about 6 percentage points higher than the value that obtains in the absence of a foreign demand for domestic currency. The optimal rate of interest now is 6.2 percent. When we increase foreign demand for domestic currency by assuming a larger value of foreign demand, $y^{f}=0.1$, then the share of foreign holdings of domestic currency in total money increases by 10 percentage points to 0.32 and the Ramsey optimal inflation rate is more than 10 percent per year. In this calibration, the benefit from 
collecting an inflation tax from foreign holdings of currency appears to strongly dominate the costs that such a high inflation tax represents for domestic agents in terms of a of a more distorted consumption-leisure choice and elevated transaction costs. The larger inflation tax revenue of the government relaxes the budget constraint of the government allowing for a decline in the Ramsey optimal tax rate of about 1.5 percentage points.

Line 4 of table 1 considers a calibration that implies a weaker demand for money both domestically and abroad. Specifically, we lower the coefficient $A$ in the transactions cost function by a factor of 4 . Because the demand for money is proportional to the square root of $A$, this parameter change implies that the ratio of money to consumption falls by a factor of two. In the Ramsey steady state, the money-to-consumption ratio falls from 26 to 13 percent. The relative importance of foreign demand for money is unchanged. It continues to account for 22 percent of total money demand. The optimal rate of inflation is virtually the same as in the baseline case. The reason why the inflation tax is virtually unchanged in this case is that the reduction in $A$ induces proportional declines in both the domestic and the foreign demands for domestic currency. The decline in foreign money demand is equivalent to a decline in $y^{f}$, and therefore induces the Ramsey planner to lower the rate of inflation. At the same time, the decline in the domestic demand for money reduces the cost of inflation for domestic agents, inducing the Ramsey planner to inflate more. In our parameterization, these two opposing effects happen to offset each other almost exactly.

Line 5 of table 1 analyzes the sensitivity of our results to raising the interest elasticity of money demand. Under a higher interest elasticity the Ramsey optimal rate of interest and inflation are lower than in the baseline case. The nominal interest rate falls from 6 to 3 percent and the inflation rate falls from about 2 percent to negative 1 percent. In this case while the Ramsey policy deviates from the Friedman rule, the deviation is not large enough to render positive inflation Ramsey optimal. The last line of the table shows that our results are very little changed when we increase the steady state debt level. We conclude from the results presented in table 1 that the tradeoff between collecting seignorage from foreign holders of domestic currency and keeping the opportunity cost of holding money low for domestic agents is overwhelmingly resolved in favor of collecting seignorage income from foreign holdings of domestic currency.

The numerical results of this section suggest that an inflation target of about 2 percent per annum may be rationalized on the basis of an incentive to tax foreign holdings of domestic currency. This argument could in principle be raised to explain average rates of inflation in countries such as the United States, which we used as a point of reference in our calibration, or in the Euro area, whose currency is held widely in eastern Europe, Russia, and certain parts of the Asia minor. However, the fact that a number of developed countries whose 
currency is not use outside of their geographic borders, such as Australia, Canada, and New Zealand, also maintain inflation targets of about two percent per year, indicates that the reason why inflation targets in the developed world are as high as observed may not originate from the desire to extract seignorage revenue from foreigners.

\section{Lump-Sum Taxation}

The reason why the benevolent government finds it desirable to deviate from the Friedman rule in the presence of a foreign demand for currency is not entirely to finance its budget with seignorage revenue extracted from foreign residents. Rather, the government imposes an inflation tax on foreign residents to increase the total amount of resources available to domestic residents for consumption. To show that this is indeed the correct interpretation of our results, we now consider a variation of the model in which the government can levy lump-sum taxes on domestic residents. Specifically, we assume that the labor income tax rate $\tau_{t}$ is zero at all times, and that the government sets lump-sum taxes to ensure fiscal solvency.

A competitive equilibrium is then given by sequences $\left\{v_{t}, v_{t}^{f}, c_{t}, h_{t}, M_{t}^{d}, M_{t}^{f}, P_{t}\right\}_{t=0}^{\infty}$ satisfying (2), (5), (7), (9), (10), (12), (13), and

$$
-\frac{U_{h}\left(c_{t}, h_{t}\right)}{U_{c}\left(c_{t}, h_{t}\right)}=\frac{1}{1+s\left(v_{t}\right)+v_{t} s^{\prime}\left(v_{t}\right)},
$$

given an interest rate sequence $\left\{R_{t}\right\}_{t=0}^{\infty}$, and the exogenous sequences $\left\{y_{t}^{f}, g_{t}\right\}_{t=0}^{\infty}$.

One can show that, given the initial condition $M_{-1}^{f}$ and the initial price level $P_{0}$, sequences $\left\{c_{t}, h_{t}, v_{t}\right\}_{t=0}^{\infty}$ satisfy the feasibility conditions (14) and (15), the labor supply equation (22), and

$$
v_{t} \geq \underline{v} \quad \text { and } \quad v_{t}^{2} s^{\prime}\left(v_{t}\right)<1
$$

if and only if they also satisfy the set of equilibrium conditions (2), (5), (7), (9), (10), (12), (13), and (22). This primal form is essentially the same as the one associated with the economy with distortionary taxes and government spending except that the implementability constraint is replaced by equation (22), which states that in equilibrium labor demand must equal labor supply. Noting that equation (22) appears in both the standard and the primal forms of the competitive equilibrium, it follows that the proof of the above statement is a simplified version of the one presented in the appendix. The Ramsey problem then consists in maximizing the utility function (1) subject to the feasibility constraints (14) and (15) and the restrictions $v_{t} \geq \underline{v}$ and $v_{t}^{2} s^{\prime}\left(v_{t}\right)<1$, given $P_{0}$ and $M_{-1}^{f}$. 
Line 7 of table 1 presents the steady state of the Ramsey equilibrium in the economy with lump-sum taxes. All parameters of the model are calibrated as in the economy with distortionary taxes. The table shows that the optimal rate of inflation equals 0.85 percent. This means that the presence of a foreign demand for money gives rise to an optimal inflation bias of about 5 percentage points above the level of inflation called for by the Friedman rule. This inflation bias emerges even though the government can resort to lump-sum taxes to finance its budget. The optimal inflation bias is smaller than in the case with distortionary taxes. This is because distortionary taxes, through their depressing effect on employment and output, make the pre-foreign-seignorage level of consumption lower, raising the marginal utility of wealth, and as a result providing bigger incentives for the extraction of real resources from the rest of the world.

The last row of table 1 displays the steady state of the Ramsey equilibrium in the case in which government consumption equals zero at all times $\left(g_{t}=0\right.$ for all $\left.t\right)$. All other things equal, the domestic economy has access to a larger amount of resources than in the economy with positive government consumption. As a result, the government has less incentives to collect seignorage income from the rest of the world. This is reflected in a smaller optimal rate of inflation of 0.59 percent. It is remarkable, however, that even in the absence of distortionary taxes and government expenditures, the government finds it optimal to deviate from the Friedman rule by about 4.5 percentage points. This result clearly shows that the ultimate purpose of positive interest rates in the presence of a foreign demand for money is the extraction of real resources from the rest of the world for private domestic consumption.

\section{Conclusion}

In this paper we have demonstrated that the presence of a foreign demand for domestic currency of the size observed for the U.S. dollar can introduce incentives for the monetary authority to generate positive rates of inflation. The inflation rate acts as a tax on foreign holdings of domestic currency that allows the domestic government to effectively extract real resources from the rest of the world. In our model, the Ramsey planner weights this incentive against the cost that inflation causes to domestic households. In the absence of a foreign demand for money, the Ramsey-optimal policy calls for adopting Friedman's rule, or deflating at the real rate of interest. We find that for plausible calibrations of our model, the tradeoff between taxing the rest of the world and keeping domestic transactions costs low is resolved in favor of taxing foreign holdings of domestic currency at rates ranging from 2 to 10 percent per year. 


\section{Appendix}

\subsection{Derivation of the Primal Form}

We first show that plans $\left\{c_{t}, h_{t}, v_{t}\right\}$ satisfying the equilibrium conditions (2), (4) holding with equality, and (5)-(13) also satisfy (15), (16), $v_{t} \geq \underline{v}$, and $v_{t}^{2} s^{\prime}\left(v_{t}\right)<1$. Let $\gamma\left(v_{t}\right) \equiv$ $1+s\left(v_{t}\right)+v_{t} s^{\prime}\left(v_{t}\right)$. Note that (5), (13), and our maintained assumptions regarding $s(v)$ together imply that $v_{t} \geq \underline{v}$ and $v_{t}^{2} s^{\prime}\left(v_{t}\right)<1$.

Let $W_{t+1}=R_{t} B_{t}+M_{t}^{d}+M_{t}^{f}$. Use this expression to eliminate $B_{t}$ from (11) and multiply by $q_{t} \equiv \prod_{s=0}^{t-1} R_{s}^{-1}$ to obtain

$$
q_{t}\left(M_{t}^{d}+M_{t}^{f}\right)\left(1-R_{t}^{-1}\right)+q_{t+1} W_{t+1}-q_{t} W_{t}=q_{t}\left[P_{t} g_{t}-\tau_{t} P_{t} F\left(h_{t}\right)\right]
$$

Sum for $t=0$ to $t=T$ to obtain

$$
\sum_{t=0}^{T}\left[q_{t}\left(M_{t}^{d}+M_{t}^{f}\right)\left(1-R_{t}^{-1}\right)-q_{t}\left(P_{t} g_{t}-\tau_{t} P_{t} F\left(h_{t}\right)\right)\right]=-q_{T+1} W_{T+1}+W_{0}
$$

In writing this expression, we define $q_{0}=1$. Solve (6) for $\tau_{t}$ and (8) for $w_{t}$ and use $F(h)=h$ to obtain $\tau_{t} F\left(h_{t}\right)=h_{t}+\frac{U_{h}\left(c_{t}, h_{t}\right)}{U_{c}\left(c_{t}, h_{t}\right)} \gamma\left(v_{t}\right) h_{t}$. Use this expression to eliminate $\tau_{t} F\left(h_{t}\right)$ from the above equation, which yields

$$
\sum_{t=0}^{T}\left\{q_{t}\left(M_{t}^{d}+M_{t}^{f}\right)\left(1-R_{t}^{-1}\right)-q_{t} P_{t}\left[g_{t}-\left[h_{t}+\frac{U_{h}\left(c_{t}, h_{t}\right)}{U_{c}\left(c_{t}, h_{t}\right)} \gamma\left(v_{t}\right) h_{t}\right]\right]\right\}=-q_{T+1} W_{T+1}+W_{0} .
$$

Use the feasibility constraint (12) to replace $h_{t}-g_{t}$ with $\left[1+s\left(v_{t}\right)\right] c_{t}-\frac{M_{t}^{f}-M_{t-1}^{f}}{P_{t}}$.

$$
\sum_{t=0}^{T} q_{t} P_{t}\left\{\frac{M_{t}^{d}+M_{t}^{f}}{P_{t}}\left(1-R_{t}^{-1}\right)+\left[1+s\left(v_{t}\right)\right] c_{t}-\frac{M_{t}^{f}-M_{t-1}^{f}}{P_{t}}+\frac{U_{h}\left(c_{t}, h_{t}\right)}{U_{c}\left(c_{t}, h_{t}\right)} \gamma\left(v_{t}\right) h_{t}\right\}=-q_{T+1} W_{T+1}+W_{0} .
$$

Use (2) and (5) to replace $\frac{M_{t}^{d}}{P_{t}}\left(1-R_{t}^{-1}\right)$ with $v_{t} s^{\prime}\left(v_{t}\right) c_{t}$

$$
\sum_{t=0}^{T} q_{t} P_{t}\left\{v_{t} s^{\prime}\left(v_{t}\right) c_{t}-\frac{M_{t}^{f}}{P_{t} R_{t}}+\left[1+s\left(v_{t}\right)\right] c_{t}+\frac{M_{t-1}^{f}}{P_{t}}+\frac{U_{h}\left(c_{t}, h_{t}\right)}{U_{c}\left(c_{t}, h_{t}\right)} \gamma\left(v_{t}\right) h_{t}\right\}=-q_{T+1} W_{T+1}+W_{0}
$$


Collect terms in $c_{t}$ and replace $1+s\left(v_{t}\right)+v_{t} s^{\prime}\left(v_{t}\right)$ with $\gamma\left(v_{t}\right)$ and rearrange

$$
\sum_{t=0}^{T} q_{t} P_{t}\left\{\gamma\left(v_{t}\right) c_{t}+\frac{U_{h}\left(c_{t}, h_{t}\right)}{U_{c}\left(c_{t}, h_{t}\right)} \gamma\left(v_{t}\right) h_{t}-\frac{M_{t}^{f}}{P_{t} R_{t}}+\frac{M_{t-1}^{f}}{P_{t}}\right\}=-q_{T+1} W_{T+1}+W_{0}
$$

Noting that by definition $q_{t} / R_{t}=q_{t+1}$ write the above expression as

$$
\sum_{t=0}^{T} q_{t} P_{t}\left\{\gamma\left(v_{t}\right) c_{t}+\frac{U_{h}\left(c_{t}, h_{t}\right)}{U_{c}\left(c_{t}, h_{t}\right)} \gamma\left(v_{t}\right) h_{t}\right\}+\sum_{t=0}^{T}\left(M_{t-1}^{f} q_{t}-M_{t}^{f} q_{t+1}\right)=-q_{T+1} W_{T+1}+W_{0}
$$

Evaluate the second sum on the left-hand side and recall that by definition $q_{0}=1$ to obtain

$$
\sum_{t=0}^{T} q_{t} P_{t}\left\{\gamma\left(v_{t}\right) c_{t}+\frac{U_{h}\left(c_{t}, h_{t}\right)}{U_{c}\left(c_{t}, h_{t}\right)} \gamma\left(v_{t}\right) h_{t}\right\}+M_{-1}^{f}-M_{T}^{f} q_{T+1}=-q_{T+1} W_{T+1}+W_{0}
$$

Using the definition of $W_{t}$ we can write the above expression as:

$$
\sum_{t=0}^{T} q_{t} P_{t}\left\{\gamma\left(v_{t}\right) c_{t}+\frac{U_{h}\left(c_{t}, h_{t}\right)}{U_{c}\left(c_{t}, h_{t}\right)} \gamma\left(v_{t}\right) h_{t}\right\}=-q_{T+1}\left(R_{T} B_{T}+M_{T}^{d}\right)+R_{-1} B_{-1}+M_{-1}^{d}
$$

Take limits for $T \rightarrow \infty$. Then by (4) holding with equality the limit of the right hand side is well defined and equal to $R_{-1} B_{-1}+M_{-1}^{d}$. Thus, the limit of the left-hand side exists. This yields:

$$
\sum_{t=0}^{\infty} q_{t} P_{t}\left\{\gamma\left(v_{t}\right) c_{t}+\frac{U_{h}\left(c_{t}, h_{t}\right)}{U_{c}\left(c_{t}, h_{t}\right)} \gamma\left(v_{t}\right) h_{t}\right\}=R_{-1} B_{-1}+M_{-1}^{d}
$$

By (7) we have that $P_{t} q_{t}=\beta^{t} U_{c}\left(c_{t}, h_{t}\right) / \gamma\left(v_{t}\right) P_{0} / U_{c}\left(c_{0}, h_{0}\right) \gamma\left(v_{0}\right)$. Use this expression to eliminate $P_{t} q_{t}$ from the above equation to obtain

$$
\sum_{t=0}^{\infty} \beta^{t}\left[U_{c}\left(c_{t}, h_{t}\right) c_{t}+U_{h}\left(c_{t}, h_{t}\right) h_{t}\right]=\left(\frac{U_{c}\left(c_{0}, h_{0}\right)}{\gamma\left(v_{0}\right)}\right)\left(\frac{R_{-1} B_{-1}+M_{-1}^{d}}{P_{0}}\right)
$$

which is (16).

We next show that the competitive equilibrium conditions imply (15). For $t=0$ equation (15) follows directly from (10) and (17). For $t>0$, use (10) to eliminate $M_{t}^{f}$ and $M_{t-1}^{f}$ from (12) to obtain:

$$
\left[1+s\left(v_{t}\right)\right] c_{t}+g_{t}=F\left(h_{t}\right)+\frac{y_{t}^{f}}{v_{t}^{f}}-\frac{y_{t-1}^{f}}{v_{t-1}^{f}} \frac{1}{\pi_{t}}
$$

Now use (7) to eliminate $\pi_{t}$. This yields: 


$$
\left[1+s\left(v_{t}\right)\right] c_{t}+g_{t}=F\left(h_{t}\right)+\frac{y_{t}^{f}}{\chi\left(v_{t}\right)}-\frac{y_{t-1}^{f}}{\chi\left(v_{t-1}\right)} \frac{U_{c}\left(c_{t-1}, h_{t-1}\right)}{R_{t-1} \gamma\left(v_{t-1}\right)} \frac{\gamma\left(v_{t}\right)}{\beta U_{c}\left(c_{t}, h_{t}\right)},
$$

Using (5) to replace $R_{t-1}$ yields (15). This completes the proof that the competitive equilibrium conditions imply the primal form conditions.

We now show that plans $\left\{c_{t}, h_{t}, v_{t}\right\}$ satisfying (15), (16), $v_{t} \geq \underline{v}$, and $v_{t}^{2} s^{\prime}\left(v_{t}\right)<1$ also satisfy the equilibrium conditions (2), (4) holding with equality, and (5)-(13). Given a plan $\left\{c_{t}, h_{t}, v_{t}\right\}$ proceed as follows. Use (5) to construct $R_{t}$ and (9) to construct $v_{t}^{f}$. Note that under the maintained assumptions on $s(v)$, the constraints $v_{t} \geq \underline{v}$ and $v_{t}^{2} s^{\prime}\left(v_{t}\right)<1$ ensure that $R_{t} \geq 1$. Let $w_{t}$ be given by (8) and $\tau_{t}$ by $(6)$.

To construct plans for $M_{t}^{d}, M_{t}^{f}, P_{t+1}$, and $B_{t}$, for $t \geq 0$, use the following iterative procedure: (a) Set $t=0$; (b) Use equation (2) to construct $M_{t}^{d}$ and equation (10) to construct $M_{t}^{f}$ (recall that $P_{0}$ is given); (c) Set $B_{t}$ so as to satisfy equation (11); (d) Set $P_{t+1}$ to satisfy (7); (e) Increase $t$ by 1 and repeat steps (b) to (e). To show that (12) holds use (15). Combining (10) and (17) with (14) it is obvious that (12) holds for $t=0$. To show that it also holds for $t>0$, combine (10), (17), and (15) to obtain:

$$
\left[1+s\left(v_{t}\right)\right] c_{t}+g_{t}=F\left(h_{t}\right)+\frac{M_{t}^{f}}{P_{t}}-\frac{M_{t-1}^{f}}{P_{t-1}}\left(1-v_{t-1}^{2} s^{\prime}\left(v_{t-1}\right)\right) \frac{U_{c}\left(c_{t-1}, h_{t-1}\right)}{\gamma\left(v_{t-1}\right)} \frac{\gamma\left(v_{t}\right)}{\beta U_{c}\left(c_{t}, h_{t}\right)},
$$

Using (5) one can write this expression as:

$$
\left[1+s\left(v_{t}\right)\right] c_{t}+g_{t}=F\left(h_{t}\right)+\frac{M_{t}^{f}}{P_{t}}-\frac{M_{t-1}^{f}}{P_{t-1}}\left(1 / R_{t-1}\right) \frac{U_{c}\left(c_{t-1}, h_{t-1}\right)}{\gamma\left(v_{t-1}\right)} \frac{\gamma\left(v_{t}\right)}{\beta U_{c}\left(c_{t}, h_{t}\right)}
$$

Finally, combining this expression with (7) yields (12).

It remains to be shown that (4) holds with equality. Follow the steps shown above to arrive at equation (23). Notice that these steps make use only of equilibrium conditions that we have already shown are implied by the primal form. Now use (7) to replace $P_{t} q_{t}$ with $\beta^{t} U_{c}\left(c_{t}, h_{t}\right) / \gamma\left(v_{t}\right) P_{0} / U_{c}\left(c_{0}, h_{0}\right) \gamma\left(v_{0}\right)$ to obtain

$\sum_{t=0}^{T} \beta^{t}\left[U_{c}\left(c_{t}, h_{t}\right) c_{t}+U_{h}\left(c_{t}, h_{t}\right) h_{t}\right]=-q_{T+1}\left(R_{T} B_{T}+M_{T}^{d}\right)\left(\frac{U_{c}\left(c_{0}, h_{0}\right)}{P_{0} \gamma\left(v_{0}\right)}\right)+\left(\frac{U_{c}\left(c_{0}, h_{0}\right)}{\gamma\left(v_{0}\right)}\right)\left(\frac{R_{-1} B_{-1}+M_{-1}^{d}}{P_{0}}\right)$

Taking limit for $T \rightarrow \infty$, recalling the definition of $q_{t}$, and using (16) yields (4) holding with equality. This completes the proof. 


\section{References}

Porter, Richard D. and Ruth A. Judson, "The Location of U.S. Currency: How Much Is Abroad?," Federal Reserve Bulletin, October 1996, 883-903.

Schmitt-Grohé, Stephanie, and Martín Uribe, "Optimal Fiscal and Monetary Policy under

Imperfect Competition," Journal of Macroeconomics 26, June 2004, 183-209. 